\title{
Uptake and release kinetics of 22 polar organic chemicals in the Chemcatcher passive sampler
}

\section{Journal Article}

\section{Author(s):}

Vermeirssen, Etiënne L. M.; Dietschweiler, Conrad; Escher, Beate I.; Voet, Jürgen van der; Hollender, Juliane

Publication date:

2013-06

Permanent link:

https://doi.org/10.3929/ethz-b-000067343

Rights / license:

In Copyright - Non-Commercial Use Permitted

Originally published in:

Analytical and Bioanalytical Chemistry 405(15), https://doi.org/10.1007/s00216-013-6878-1 


\title{
Uptake and release kinetics of 22 polar organic chemicals in the Chemcatcher passive sampler
}

\author{
Etiënne L. M. Vermeirssen - Conrad Dietschweiler • \\ Beate I. Escher • Jürgen van der Voet • Juliane Hollender
}

Received: 17 December 2012 / Revised: 18 February 2013 / Accepted: 26 February 2013 /Published online: 27 March 2013

(C) Springer-Verlag Berlin Heidelberg 2013

\begin{abstract}
The Chemcatcher passive sampler, which uses Empore $^{\mathrm{TM}}$ disks as sampling phase, is frequently used to monitor polar organic chemicals in river water and effluents. Uptake kinetics need to be quantified to calculate timeweighted average concentrations from Chemcatcher field deployments. Information on release kinetics is needed if performance reference compounds (PRCs) are used to quantify the influence of environmental conditions on the uptake. In a series of uptake and elimination experiments, we used Empore ${ }^{\mathrm{TM}}$ SDB disks (poly(styrenedivinylbenzene) copolymer modified with sulfonic acid groups) as a sampling phase and 22 compounds with a $\log K_{\text {ow }}$ (octanol-water partitioning coefficient) range from -2.6 to 3.8. Uptake experiments were conducted in river water or tap water and lasted up to 25 days. Only 1 of 22 compounds (sulfamethoxazole) approached equilibrium in the uptake trials. Other compounds showed continuing non-linear uptake, even after 25 days. All compounds could be released
\end{abstract}

Electronic supplementary material The online version of this article (doi:10.1007/s00216-013-6878-1) contains supplementary material, which is available to authorized users.

E. L. M. Vermeirssen $(\bowtie) \cdot$ C. Dietschweiler · B. I. Escher •

J. van der Voet $\cdot J$. Hollender

Eawag, Swiss Federal Institute of Aquatic Science

and Technology, Überlandstrasse 133,

8600 Dübendorf, Switzerland

e-mail: etienne.vermeirssen@eawag.ch

J. Hollender

Institute of Biogeochemistry and Pollutant Dynamics,

ETH Zürich, 8092 Zürich, Switzerland

B. I. Escher

National Research Centre for Environmental Toxicology (Entox),

The University of Queensland, 39 Kessels Road,

Brisbane, QLD 4108, Australia

Present Address:

E. L. M. Vermeirssen

Oekotoxzentrum, Eawag/EPFL, Überlandstrasse 133,

8600 Dübendorf, Switzerland from SDB disks, and desorption was proportionally higher in disks loaded for shorter periods. Desorption showed two-phase characteristics, and desorption was proportionally higher for passively sorbed compounds compared to actively loaded compounds (active loading was performed by pulling spiked river water over SDB disks using vacuum). We hypothesise that the two-phase kinetics and better retention of actively loaded compounds - and compounds loaded for a longer period - may be caused by slow diffusion of chemicals within the polymer. As sorption and desorption did not show isotropic kinetics, it is not possible to develop robust PRCs for adsorbent material like SDB disks.

Keywords Passive sampling · Chemcatcher · POCIS . Pharmaceuticals $\cdot$ Biocides

\section{Introduction}

Passive sampling technology has been used successfully to monitor volatile contaminants in the air [1] and organic contaminants in the water [2]. During the last decade, there has been an increasing interest in polar organic compounds in the aquatic environment. Although these compounds do not readily accumulate in organisms, their continuous use and discharge patterns make them pseudo persistent, and they have been shown to affect wildlife [3, 4]. As a result of this interest, and increasing monitoring requirements for such compounds [5, 6], there is a growing interest to develop passive samplers for polar organic compounds [7].

Currently, there are two main types of samplers for polar organic compounds: POCIS (polar organic chemical integrative sampler) [8] and Chemcatcher [9]. Both use adsorbent material such as Oasis HLB or styrenedivinylbenzene (SDB) polymers, which are well suited to undergo reversed phase and ion exchange interactions with polar substances. Studies dealing with these samplers typically cover the establishment 
of sampling rates $\left(R_{\mathrm{S}}\right.$, in liters per day) in the lab and subsequent field deployments. The amounts of passively sampled chemicals in the field are then divided by the sampling ratesmultiplied by the deployment time - to arrive at time weighted average (TWA) water concentrations (e.g. [8, 10, 11]).

A Chemcatcher is based on Empore ${ }^{\mathrm{TM}}$ disks, where the sorbents are immobilised in a Teflon support and can be exposed to the water either with or without a diffusionlimiting membrane. In contrast, membranes are needed to retain the sorbent in a POCIS. If Empore ${ }^{\mathrm{TM}}$ disks are used without a membrane, they will sample a wider range of chemicals and with higher sampling rates [12]. Low selectivity is very important when combining passive sampling with biological analysis, to prevent exclusion of unknown toxicants [13]. Higher sampling rates suit relatively short deployment windows (a few days) for monitoring selected peak events. Using an Empore ${ }^{\mathrm{TM}}$ disk without a membrane, even with a sampling window of a few days, provides enough extract to run multiple chemical and biological analyses [14].

In order to use Empore ${ }^{\mathrm{TM}}$ disks for monitoring pollutants and for calculating TWA concentrations, information on $R_{\mathrm{S}}$ is needed, and it is important to know the duration of the integrative sampling period (i.e. the time required for the sorbent to reach half the equilibrium state). One aim of our study was to provide this information and perform sorption experiments for a suite of 22 chemicals. To have a broad scope, we covered chemicals with a large range of hydrophobicity; $\log K_{\mathrm{ow}}$ (octanol-water partitioning coefficients) ranged from -2.6 to 3.8. Furthermore, the compounds covered several application classes: herbicides, pharmaceuticals and industrial chemicals as well as neutral and ionogenic compounds. One 8-day sorption experiment was conducted in an environmentally relevant matrix - river water carrying some effluent- to ensure that sorption kinetics were established under conditions similar to those that prevail when the passive sampler is used in field studies. A second experiment ran for 25 days and was performed under accelerated conditions (higher temperature, reduced aqueous boundary layer) and in tap water to get a better understanding about the maximal integrative period.

Beside the focus on sorption, a second main aim of our study was to address desorption. Understanding the desorption process is important when considering the behaviour of a sampler after a peak concentration event [15]. Understanding the desorption process is also important when considering the use of performance reference compounds (PRCs) in passive samplers [16]. PRCs are usually isotope-labelled compounds that are pre-loaded into the sampler. From the release of PRCs during deployment, an application specific exchange rate constant can be derived that allows one to quantify/predict in situ sampling rates [17]. This approach produces a better estimate of the TWA concentration.

A few recent studies have touched on desorption of chemicals from POCIS [16] and Chemcatchers [18, 19,
20], but their results were controversial. Shaw et al. [19] found that the dissipation rates of PRCs could not be used to estimate the effect of field exposure conditions on uptake rates of Empore ${ }^{\mathrm{TM}}$ SDB disks. However, Camilleri et al. [20] observed close to isotropic exchange for 3 of 20 compounds that were tested on Empore ${ }^{\mathrm{TM}} \mathrm{C} 18$ disks covered with a polyethersulfone membrane. Finally, Mazzella et al. [16] proposed labelled deisopropylatrazine as a suitable PRC for the sampling of herbicides by POCIS. A prerequisite for the correct application of PRCs is isotropic uptake and release kinetics $[16,20]$. However, polar sorbent phases like SDB (poly(styrenedivinylbenzene) copolymer modified with sulfonic acid groups) are regarded as adsorbents, and uptake and release in such phases is often anisotropic [21].

In the current study, desorption was addressed in three ways. First, compounds were loaded passively in spiked river water, next it was assessed how well sorbed compounds desorb into river water. Second, to ascertain that sorbed compounds desorbed rather than being lost from the disk via another process (e.g. degradation of compounds after sorption to the disk), we passively sorbed compounds and then determined desorption mass balances in a closed environment (a tap water-filled beaker). Third, in order to assess the "maximum" potential for desorption and investigate if the way compounds are loaded affect the desorption kinetics, compounds were loaded passively and actively (by means of solid phase extraction, SPE) from river water onto SDB disks, subsequently desorption kinetics were assessed in deionised water.

\section{Methods}

Preparation and processing of Empore ${ }^{\mathrm{TM}}$ SDB-RPS disks

Empore $^{\mathrm{TM}}$ SDB disks $(47 \mathrm{~mm}$ diameter, $0.5 \mathrm{~mm}$ thick; Infochroma; AG, Zug, Switzerland) were conditioned with methanol and water [14] and fitted in a steel $(2 \mathrm{~mm})$ rectangular housing. An SDB disk was placed on a 70 by $100-\mathrm{mm}$ back plate, and a $70-\mathrm{mm}$ square cover plate, with a $40-\mathrm{mm}$ diameter hole, was placed over the disk. Both plates were screwed tight with four bolts (see Electronic supplementary material (ESM) Fig. S1-S3). After deployment, the housing was opened, and disks were stored in $7 \mathrm{ml}$ acetone at $-20{ }^{\circ} \mathrm{C}$.

Before further processing, frozen SDB disks in acetone were allowed to reach room temperature and shaken on an orbital shaker (30 min). Subsequently, the acetone was transferred to a new vial, and methanol was added to the disk and the disk shaken again $(30 \mathrm{~min})$. The acetone fraction was reduced in a vacuum centrifuge to around $0.5 \mathrm{ml}$, and the methanol fraction was added to the acetone. The solvent mixture was filtered $(0.47 \mu \mathrm{m})$, reduced to below $0.5 \mathrm{ml}$ and then made up to $1 \mathrm{ml}$ with methanol. 
Channel system running with river water

Several modifications were made to a channel system (see [22]) that runs with water from a river (Chriesbach) that carries approximately $10 \%$ of treated sewage effluent and thus background concentrations of a cocktail of polar organic contaminants (see ESM Fig. S4). A 200-L sedimentation tank was installed (Fig. S5, ESM), over which $20 \mathrm{Lh}^{-1}$ of river water was pumped into the channel system, leading to one exchange per day (system volume $=480 \mathrm{~L}$ ). The water in the system was recirculated continuously at a rate of $20 \mathrm{~m}^{3} \mathrm{~h}^{-1}$, leading to a slight elevation in water temperature $\left(2-8{ }^{\circ} \mathrm{C}\right.$ above that of fresh river water). Recirculating the water also induced an increase in $\mathrm{pH}$. In order to prevent scaling, a $\mathrm{pH}$ control was installed that added diluted $\mathrm{HCl}(4-5 \%)$ to the channel system and maintained the $\mathrm{pH}$ near that of the river (ca. 8).

The recirculating water ran through a $0.5-\mathrm{m}$ wide and 2.0 $\mathrm{m}$ long and $0.15-\mathrm{m}$ high Plexiglas channel with a water level of $0.1 \mathrm{~m}$. The inside of both channel walls was fitted with 2-m long Plexiglas inserts with ten evenly spaced pockets into which passive samplers could be placed (Fig. S3 and S4, ESM). When samplers were deployed in the channel, a 70 by $100-\mathrm{mm}$ PVC block (20 $\mathrm{mm}$ strong) with a $40 \mathrm{~mm}$ diameter hole was placed on top of the steel housing, with the hole in the PVC block matching that of the steel sampler housing (Fig. S2, ESM). This approach created a cavity that is similar to the one for standard Teflon Chemcatcher housing [23]. Flow rates in the channel were between 0.08 and $0.10 \mathrm{~ms}^{-1}$ at the sides and 0.13 to $0.14 \mathrm{~ms}^{-1}$ in the centre.

At the start of a sorption experiment, a single dose of compounds (for a list of compounds see Table 1) was spiked into the channel system, to bring the concentration in the water to the desired level (typically $1 \mu \mathrm{gL}^{-1}$ ). To maintain the desired aqueous concentrations, chemicals were dosed into the water by means of an HPLC pump $\left(1 \mathrm{mlmin}^{-1}\right)$. Samplers were usually deployed after the system had been

Table 1 Studied compounds are listed with their $\log K_{\text {ow }}$, sampling rates over the first $24 \mathrm{~h}$ of deployment in Experiments 1 and $2\left(R_{\mathrm{S}}\right)$ and the loss of sorbed compounds observed in Experiment 3

\begin{tabular}{|c|c|c|c|c|c|c|c|c|c|}
\hline & $\begin{array}{l}\text { Class of } \\
\text { compound }\end{array}$ & $\mathrm{p} K \mathrm{a}$ & $\begin{array}{l}\log K_{\mathrm{ow}}{ }^{\mathrm{a}} \\
\left(\log D_{\mathrm{ow}}, \mathrm{pH} 8\right)\end{array}$ & $\begin{array}{l}R_{\mathrm{S}}\left(\mathrm{Lday}^{-1}\right) \\
\text { river water, } \\
\text { channel }\end{array}$ & $\begin{array}{l}R_{\mathrm{S}}\left(\mathrm{Lday}^{-1}\right) \\
\text { tap water, } \\
\text { circular tank }\end{array}$ & $\begin{array}{l}\text { Loss in } \\
\text { channel } \\
(\mathrm{L} 2 \mathrm{~d} ; \%)\end{array}$ & $\begin{array}{l}\text { Loss in } \\
\text { channel } \\
(\mathrm{L} 12 \mathrm{~d} ; \%)\end{array}$ & $\begin{array}{l}\text { Loss in } \\
\text { beaker } \\
(\%)\end{array}$ & $\begin{array}{l}\text { Recovery } \\
\text { in beaker } \\
(\%)\end{array}$ \\
\hline 5-Methylbenzotriazole & Anticorrosive & 8.9 & $1.61(1.56)$ & 0.29 & 0.09 & 10 & 19 & $\mathrm{c}$ & 19 \\
\hline Atrazine & Herbicide & & 2.60 & 0.37 & 0.76 & 20 & 13 & 32 & 93 \\
\hline Desethylatrazine & Metabolite & & 1.51 & 0.29 & 0.47 & 46 & 35 & 58 & 111 \\
\hline Deisopropylatrazine & Metabolite & & 1.15 & 0.21 & 0.34 & 63 & 42 & 68 & 118 \\
\hline Hydroxyatrazine & Metabolite & & 1.75 & 0.13 & 0.25 & 36 & 22 & 56 & 138 \\
\hline Benzotriazole & Anticorrosive & 8.37 & $1.44(1.29)$ & 0.19 & 0.05 & -37 & 27 & $\mathrm{c}$ & 14 \\
\hline Caffeine & Stimulant & & -0.07 & 0.23 & 0.41 & 52 & 42 & 75 & 137 \\
\hline Carbamazepine & Anticonvulsant & & 2.45 & 0.34 & 0.77 & 13 & 13 & 24 & 105 \\
\hline Carbendazim & Fungicide & & 1.52 & 0.33 & 0.48 & 34 & 21 & $\mathrm{c}$ & 22 \\
\hline Chloridazon & Herbicide & & 1.14 & 0.25 & 0.47 & 57 & 35 & 50 & 84 \\
\hline Diazinon & Insecticide & & 3.81 & 0.42 & 0.75 & 1 & 1 & 37 & 64 \\
\hline Diclofenac & Analgesic & 4.15 & $4.51(0.66)$ & 0.24 & 0.45 & 13 & 13 & 54 & 92 \\
\hline Diuron & Herbicide & & 2.68 & 0.38 & 0.80 & 22 & 15 & 33 & 93 \\
\hline Irgarol & Herbicide & & 3.29 & 0.39 & 0.75 & 12 & 7 & 26 & 80 \\
\hline Isoproturon & Herbicide & & 2.87 & 0.38 & 0.73 & 22 & 12 & 36 & 89 \\
\hline Mecoprop & Herbicide & 3.11 & $3.13(-1.76)$ & 0.13 & 0.24 & 66 & 61 & 83 & 113 \\
\hline Metolachlor & Herbicide & & 3.13 & 0.40 & 0.80 & $\mathrm{~b}$ & $\mathrm{~b}$ & $\mathrm{~b}$ & $\mathrm{~b}$ \\
\hline Phenazone & Analgesic & & 0.38 & 0.41 & 0.45 & 54 & 35 & 62 & 88 \\
\hline Sufamethoxazole & Antibiotic & 5.6 & $0.89(-1.51)$ & 0.11 & 0.18 & 72 & 65 & 97 & 122 \\
\hline Sulcotrione & Herbicide & 3.13 & $2.31(-2.56)$ & 0.07 & 0.10 & 51 & 53 & $\mathrm{c}$ & 175 \\
\hline Terbutryn & Herbicide & & 3.74 & 0.38 & 0.76 & 17 & 11 & 27 & 78 \\
\hline Terbuthylazine & Herbicide & & 3.21 & 0.39 & 0.77 & 12 & 11 & 24 & 90 \\
\hline
\end{tabular}

${ }^{a}$ Experimental $\log K_{\mathrm{ow}}$ values were taken from the PhysProp Database, Syracuse Research Corporation (http://www.syrres.com/what-wedo/databaseforms.aspx?id=386; accessed January 24, 2012); estimated $\log K_{\text {ow }}$ values were taken from the ALOGPS web-site (www.vcclab.org/lab/alogps/; accessed January 24, 2012); partition coefficients in brackets are normalised to the fraction of the neutral species at the $\mathrm{pH}$ of river water $(\mathrm{pH}=8), D_{\mathrm{ow}}(\mathrm{pH} 8)=1 /\left(1+10^{(8-\mathrm{p} K \mathrm{a})}\right) K_{\mathrm{ow}}$

${ }^{\mathrm{b}}$ Metolachlor was not spiked in Experiment 3

${ }^{\mathrm{c}}$ Loss of sorbed compounds is only listed when recovery (mass balance) in the beaker was within 60 to $140 \%$ 
left to "equilibrate" for $2-4$ days. During experiments, hourly water samples were taken from the channel system using automated samplers. Aqueous concentrations of the chemicals were measured in 24 -h composite samples.

Circular tank for lab studies with tap and deionised water

SDB disks in steel housings were placed along the wall of a round Plexiglas tank $(0.8 \mathrm{~m}$ diameter, $150 \mathrm{~mm}$ high, $70 \mathrm{~mm}$ water level; ESM, Fig. S6). Degassed water (Fig. S7, ESM) entered the tank near the wall, excess water drained from the tank via a standpipe in the centre. The centre of the tank also held a $0.3-\mathrm{m}$ diameter and $0.2 \mathrm{-m}$ high stainless steel mesh (5 $\mathrm{mm}$ diameter) circle that contained two submersible pumps. The pumps drew water from within the mesh circle and ejected the water through a single plastic tube that ran from the mesh to the edge of the tank wall, producing a circular water flow within the tank. The flow rate past the surface of the exposed disks was between 0.12 and $0.14 \mathrm{~ms}^{-1}$. Water entering the tank could be dosed with compounds using an HPLC pump $\left(1 \mathrm{mlmin}^{-1}\right)$. During experiments, aqueous concentrations were assessed by taking daily grab samples.

Five sorption and desorption experiments-Fig. 1

\section{Experiment 1 -sorption in river water}

The channel system was spiked and dosed with chemicals to reach aqueous concentrations of $1 \mu \mathrm{gL}^{-1}$. Eighteen SDB disks were placed in the channel, and duplicate disks were removed over 8 days.

\section{Experiment 2-sorption in tap water}

The circular tank was flushed with tap water, and compounds were dosed to reach aqueous concentrations of $0.4 \mu \mathrm{gL}^{-1}$. The concentrations were reduced compared to Experiment 1 (and Experiment 3) because the tap water matrix is less problematic in terms for LC-MS/MS analysis in terms of ion suppression in comparison to river water matrix. Twenty-two SDB disks were placed in the tank, and duplicate disks were removed over 25 days.

\section{Experiment 3-desorption in river water}

The channel was spiked to reach aqueous concentrations of $0.5-1 \mu \mathrm{gL}^{-1}$. Fourteen disks were placed in the channel to be loaded for 12 days ("L12d" disks). On day 11, a set of 18 fresh disks was placed in the centre of the channel in the steel housing only (no PVC block) - to facilitate a rapid sorption of compounds. These disks were to be loaded for 2 days ("L2d" disks). Dosing of chemicals was increased threefold on day 11 with the goal to bring the mass of chemicals sorbed by the L2d disks close to the level of the mass sorbed by the L12d disks.

After 12 days, four L12d and four L2d disks were removed to serve as the initial data point for desorption $\left(t_{0}\right)$. Four additional L2d disks were removed and used in Experiment 4 ("Mass balance of desorption in tap water"). Dosing of chemicals was stopped, and the channel system was completely drained and quickly flushed twice with fresh river water. The remaining L2d disks were fitted with PVC blocks and moved to the pockets in the sides of the channel. Desorption in river water was monitored by removing pairs of $\mathrm{L} 2 \mathrm{~d}$ and L12d disks over 12 days. The desorption potential of compounds from L2d and L12d disks into river water (i.e. percentage loss from SDB disk) was calculated by dividing the mass of a compound remaining in the disks at 12 days by the mass of the compound at the start of desorption $\left(t_{0}\right)$ and subtracting it from $100 \%$.

\section{Experiment 4-mass balance of desorption in tap water}

Four L2d disks were moved to the lab, and pairs of disks were placed in two 5-L beakers that were placed on magnetic stirrers (Fig. S8, ESM). Tap water $\left(1.5 \mathrm{~L}, 25^{\circ} \mathrm{C}\right)$ was added to each beaker, and water in the centre of a beaker was displaced by means of a $250-\mathrm{mL}$ bottle that was

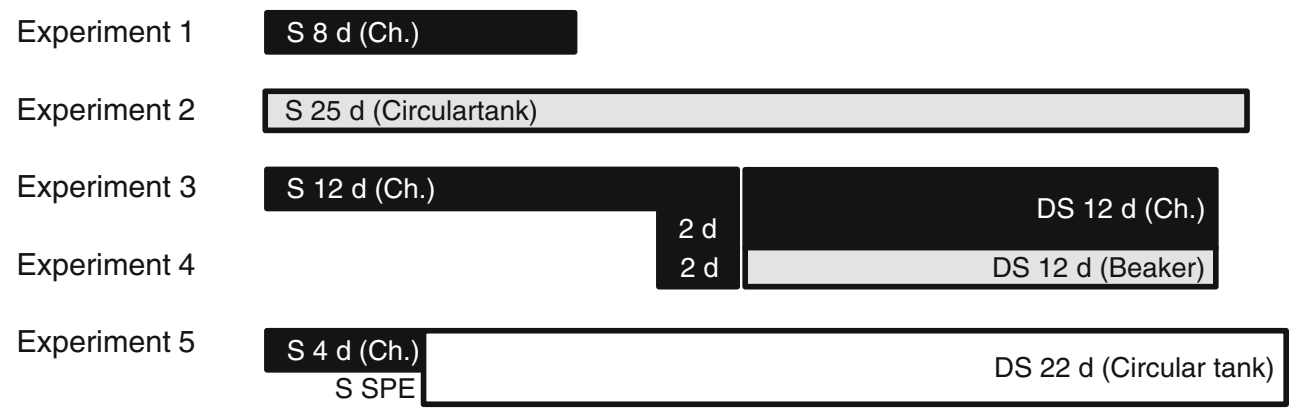

Fig. 1 Scheme of five sorption $(S)$ and desorption experiments with Empore $^{\mathrm{TM}}$ SDB disks. Experiments were conducted in a channel running with river water $(C h)$, a circular tank flushed with tap or deionised water, or a beaker filled with tap water; the various matrices are shown in different shades (river water, black; tap water, grey; deionised water, white). In Experiment 5, compounds were also sorbed onto SDB disks by pulling spiked river water through the disks (SPE) 
suspended about $20 \mathrm{~mm}$ above the stir bar. This ensured a quasi-laminar flow of $0.1 \mathrm{~ms}^{-1}$ past the walls of the beakers [11]. Disks in steel holders were suspended against the wall of the beaker with the exposed disk surface facing inwards. Water was renewed every 2 days and stored at $4{ }^{\circ} \mathrm{C}$ for analysis. The SDB disks were removed after 12 days.

The mass balance was calculated by adding the mass of a chemical found in the combined water samples that had been collected over 12 days and the mass of a compound remaining in the disks at 12 days, and offsetting this against the initial mass of the chemical on the disks.

\section{Experiment 5-desorption into deionised water}

A set of 23 disks was placed in the middle of the channel that was spiked to $1 \mu \mathrm{gL}^{-1}$; no PVC blocks were used to facilitate rapid sorption. After 4 days, three disks were sampled to serve as the initial data point for desorption $\left(t_{0}\right)$. The remaining disks were placed along the wall of the circular tank that was continuously flushed with deionised water $\left(0.8 \mathrm{Lmin}^{-1}\right)$. Pairs of disks were removed over a period of 22 days.

In addition to the 23 channel loaded disks, a set of six SDB disks was loaded with $1 \mathrm{~L}$ of spiked channel water using a vacuum disk manifold system [24]. Two disks served as a reference $\left(t_{0}\right)$, and the other four disks were placed in the circular tank. Two of the four disks were removed after 4.5 days, the remaining two after 22 days.

Chemical analysis of 22 chemicals with $\log K_{\text {ow }}$ values between -2.6 and 3.8

The compounds used and analysed in this study are listed in Table 1 along with their $\log K_{\mathrm{ow}}$. One hundred microlitres of a 1-ml SDB disk extract (or a diluted extract) was spiked with $100 \mu \mathrm{l}$ of a mix of 19 isotope-labelled internal standards and $20 \mathrm{ml}$ of nanopure water was added. Water samples (either 4 or $20 \mathrm{ml}$ ) were also spiked with internal standards. Samples were enriched with an online SPE system followed by HPLCMS/MS analysis [25]. Detection was carried out in the selected reaction mode using one transition as quantifier and another as qualifier. Limits of quantification were determined by signal-to-noise ratio of 10 and the difference between quantifier and qualifier amounting to less than $20 \%$. All the reported data satisfied these QA/QC criteria.

Data analysis

Sorption data were fitted with Eq. 1, which requires that concentrations of the compounds in water $\left(C_{\mathrm{w}}\right.$, nanograms per litre) are constant during the sorption experiment [26].

$m_{i}(t)=C_{\mathrm{w}} K_{\mathrm{SDBw}}\left(1-e^{-k_{\mathrm{e}} t}\right) m_{\mathrm{SDB}}$
The amount of a compound ( $i$ ) sorbed onto the SDB disk is denoted $m_{i}$ (nanograms per disk). $K_{\mathrm{SDBw}}$ is the apparent sorption coefficient of the analyte between SDB and water (litres per kilogram); $k_{\mathrm{e}}$ (days) is the exchange rate coefficient; $m_{\mathrm{SDB}}$ is the mass of the SDB disk (322 mg).

For illustrative purposes, the diuron sorption data were fitted with a two-phase exponential model (Eq. 2).

$m_{\text {diuron }}(t)=m_{\text {diuron,rapid }}\left(1-e^{-k_{\text {rapid }} t}\right)+m_{\text {diuron,slow }}\left(1-e^{-k_{\text {slow }} t}\right)$

Where $m_{\text {diuron, rapid }}$ and $m_{\text {diuron, slow }}$ are the equilibrium amounts of diuron (nanograms per disk ${ }^{-1}$ ) that show a rapid and slow uptake, $k_{\text {rapid }}$ and $k_{\text {slow }}$ are the rate constants for the rapid and slow uptake processes (days).

Data from desorption experiments in river water were fitted with Eq. 3.

$m_{i}(t)=\left(m_{i}(t=0)-K_{\mathrm{SDBw}} C_{\mathrm{w}} m_{\mathrm{SDB}}\right) e^{-k_{\mathrm{e}} t}+K_{\mathrm{SDBw}} C_{\mathrm{w}} m_{\mathrm{SDB}}$

$m_{i}(t=0)$ signifies the amount of a compound $(i)$ in the sampler at the start of desorption and $C_{\mathrm{w}}$ is the average background concentration during the desorption experiment in river water. During desorption in deionised water, $C_{\mathrm{w}}$ is 0 and the fit was carried out assuming a first-order exponential release. Desorption data were also fitted with a two-phase exponential dissociation model (Eq. 4).

$m_{i}(t)=m_{i, \text { rapid }}(t=0) e^{-k_{\text {rapid }} t}+m_{i, \text { slow }}(t=0) e^{-k_{\text {slow }} t}$

Where $m_{i \text {, rapid }}(t=0)$ and $m_{i \text {, slow }}(t=0)$ are the amounts of the initially sorbed compound (nanograms per disk) that follow a rapid and slow desorption process and $k_{\text {rapid }}$ and $k_{\text {slow }}$ are the rate constants for the rapid and slow desorption processes (per day).

The sampling rate $\left(R_{\mathrm{s}}\right.$; litres per day) was calculated for various time slots using Eq. 5.

$R_{\mathrm{s}}(t)=\frac{m_{i}}{C_{\mathrm{w}} t}$

\section{Results and discussion}

Extended curvilinear sorption on Empore ${ }^{\mathrm{TM}}$ SDB disks

One of our aims was to investigate the length of the integrative sampling period of a range of compounds by SDB disks. Based on previous studies [14, 27], it was expected that the more hydrophilic compounds $\left(\log K_{\text {ow }}<2\right)$ would noticeably start approaching equilibrium with SDB disks within the 8 days of deployment in spiked river water. 
However, this was only the case for sulfamethoxazole (Fig. 2a). Most compounds followed a non-linear uptake process, also the more hydrophobic compounds in our test set (e.g. carbamazepine and terbuthylazine; Fig. 2b, c; see Fig. S9, ESM, for all graphs). Two additional sorption experiments in the channel with river water-with fewer time points sampled - produced similar results (data not shown).

Based on the results from Experiment 1, the aim of Experiment 2 was to achieve equilibrium for most of the compounds. The sorption experiment conducted in tap water was carried out at a higher temperature, higher flow rate and using the shallow housing only (no PVC block) to accelerate the sorption kinetics compared to conditions in the channel (see $R_{\mathrm{S}}$ values in Table 1). However, the only compound that approached an equilibrium state in Experiment 2 was again sulfamethoxazole (Fig. 2d). Other compounds were still clearly in the curvilinear sorption phase, even after 25 days (e.g. carbamazepine and terbuthylazine; (Fig. 2e-f; see Fig. S10, ESM, for all graphs) indicating that the uptake until equilibrium extends much longer than expected.

As sulfamethoxazole approached equilibrium in both sorption experiments, it produced fairly robust fit parameters with the one-phase sorption model (Eq. 1). The estimated value for $K_{\mathrm{SDBw}}$ for sulfamethoxazole in river water was 784 and somewhat lower than the $K_{\mathrm{SDBw}}$ estimated for sorption in tap water, 1,208 . This may be explained by the fact that tap water had a lower $\mathrm{pH}(\mathrm{pH} 7)$ than river water $(\mathrm{pH} 8)$, and thus, more neutral sulfamethoxazole was present in tap water. The difference in $k_{\mathrm{e}}$ is perhaps more striking; the sampling rate of sulfamethoxazole from tap water was $40 \%$ higher than from river water $(0.15$ versus $0.11 \mathrm{~L}$ for the first $24 \mathrm{~h})$, yet the $k_{\mathrm{e}}$ in tap water was $30 \%$ lower ( 0.34 versus 0.47 days). It is counterintuitive that the fastest kinetics were obtained under conditions of lower flow rate and deeper housing (thicker aqueous boundary layer) as well as a lower temperature. Again, these observations point to a possible effect of the matrix - river water or tap water-on the sorption process, for example the $\mathrm{pH}$. This could be addressed in specific experiments, for example, by directly comparing river water and tap water in parallel setups (i.e. two circular tanks) or by varying the $\mathrm{pH}$ of either tap water or river water.

Sampling rates for the first day of deployment

Both sorption experiments contained a sampling window that was close to the first $24 \mathrm{~h}$ of deployment. Consequently, experimental sampling rates were calculated for these sampling windows and adjusted to $24 \mathrm{~h}$ rates, i.e. the sampling rate for the
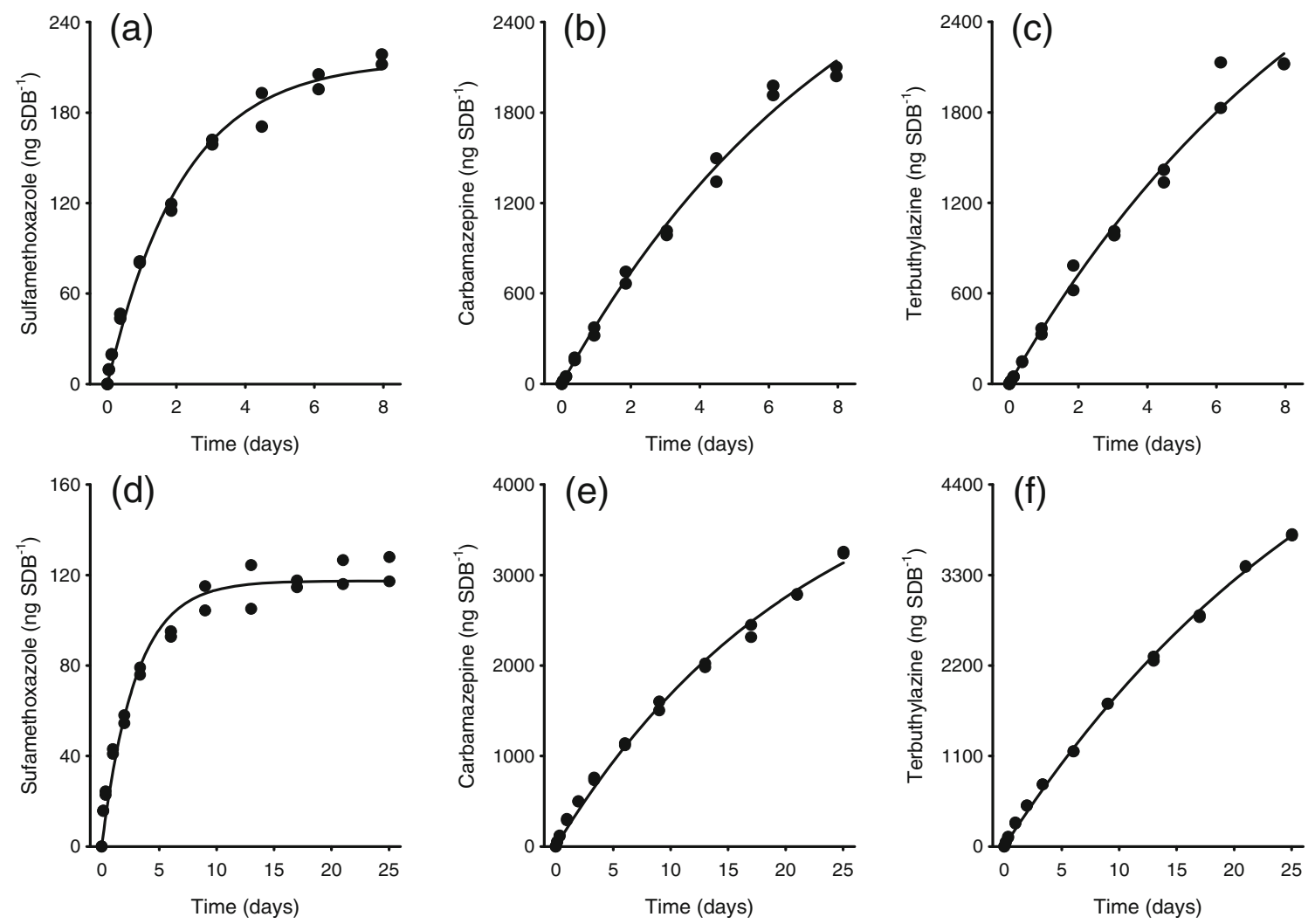

Fig. 2 Top panel: sorption of sulfamethoxazole (a), carbamazepine (b) and terbuthylazine (c) by Empore ${ }^{\mathrm{TM}} \mathrm{SDB}$ disks from river water (Experiment 1). Lower panel: sorption of sulfamethoxazole (d), carbamazepine (e) and terbuthylazine (f) from tap water (Experiment 2). Lines are fits with a one-phase model (Eq. 1) 
first day of deployment. This $R_{\mathrm{S}}$ ranged between 0.1 and $0.4 \mathrm{~L}$ day $^{-1}$ for all compounds sorbed from river water (Table 1$)$. The $R_{\mathrm{S}}$ values of all compounds sorbed from tap water ranged between 0.1 and $0.8 \mathrm{Lday}^{-1}$, with the exception of 5methylbenzotriazole and benzotriazole. The sorption curves of these two compounds were erratic and $R_{\mathrm{S}}$ values were low. One reason for this may be adsorptive processes between the compounds and the stainless steel disk holders [28], but it is unclear why this effect did not occur in river water.

Sampling rates from both sorption trials were highly correlated with the exception of the two anticorrosives $(r=$ $0.92 ; n=20$ ), this underlines the general robustness of both data sets. When $R_{\mathrm{S}}$ values from both sorption trials (Table 1) were fitted with a linear model without an intercept, the slope of the regression was almost 1.85 . This shows that the experimental conditions in the circular tank led to an accelerated sorption process that had a fairly constant effect $(+85 \%)$ across the range of compounds we tested (Fig. 3a). As mentioned earlier, accelerated sorption (and higher $R_{\mathrm{S}}$ values) in tap water was expected, due to the higher temperatures ( 26 compared to $13{ }^{\circ} \mathrm{C}$ ), higher flow rate (12 compared to $8 \mathrm{cms}^{-1}$ ) and the absence of the PVC block and thus a more direct effect of flow closer to the surface of the SDB disk (2 versus $22 \mathrm{~mm}$ deep cavity). In fact, we expected that the effect of housing alone - reducing the aqueous boundary layerwould induce a twofold higher sampling rate in Experiment 2, based on a study by Lobpreis et al. [23].

Generally, $R_{\mathrm{S}}$ increased with the $\log K_{\mathrm{ow}}$ of the sampled compound. Although we do not know the underlying relationship, a linear model produced a reasonable fit $\left(R^{2}=\right.$ 0.68 ; $n=22$; Fig. 3b). Two compounds were particularly far from the linear relationship, phenazone and hydroxy atrazine. It is difficult to evaluate why these two compounds appear as outliers. Perhaps $\log K_{\text {ow }}$ is only a partial descriptor of the interactions between the tested compounds and the SDB disk. Moreover, the quality of the fit will also depend on the accuracy of $\log K_{\text {ow }}$ values and the availability of information on speciation to correctly adjust $\log K_{\text {ow }}$ values to the fraction of neutral species. For example, several zwitter ion structures exist for hydroxy atrazine at neutral $\mathrm{pH}$ [29] which causes that $\log K_{\text {ow }}$ is only a partial descriptor of the interactions between the compound and the SDB disk and less interaction is expected. The $\log K_{\text {ow }}$ of phenazone we used $(0.38$, see Table 1) is an experimental value [30] and phenazone is neutral at the tested $\mathrm{pH}$. However, several prediction methods (www.vcclab.org/lab/alogps/) estimate a higher $\log K_{\text {ow }}$ value (1.14 \pm 0.66$)$; a higher $\log K_{\mathrm{ow}}$ for phenazone would improve the correlation between $\log K_{\mathrm{ow}}$ and $R_{\mathrm{S}}$ values. With phenazone and hydroxyl atrazine removed from the data set, $\log K_{\text {ow }}$ explains $92 \%$ of the variability in $R_{\mathrm{S}}$ values $(n=20)$. In Experiment 2, and excluding 5-methylbenzotriazole and benzotriazole, $\log K_{\text {ow }}$ explained $81 \%$ of the variability in $R_{\mathrm{S}}$ values. Hydroxy atrazine was again furthest removed from the linear relationship (Fig. 3c; $R^{2}=0.81, n=20$; without hydroxy atrazine, $R^{2}=0.88, n=19$ ).

Compounds with a $\log K_{\text {ow }}$ between -2.6 and 3.8 desorb from SDB disks

The desorption experiments clearly show that the sorption process is readily reversible. Of the 22 compounds, sulfamethoxazole generally showed the largest degree of desorption. For example, sulfamethoxazole that passively sorbed onto SDB disks, either on L2d or L12d disks, mostly desorbed from the disks over the 12 days where spiking of the channel ceased and aqueous concentrations dropped to the background levels of the river (between 20 and $70 \mathrm{ngL}^{-1}$; Fig. 4a). Similar patterns were observed for the other more polar compounds in the test set $\left(\log K_{\mathrm{ow}}<2\right)$. An exception being benzotriazole; background levels of benzotriazole in the river water were always elevated, exceeding the level dosed into the channel (ranging up to $8 \mu \mathrm{gL}^{-1}$ ). Consequently, after the loading

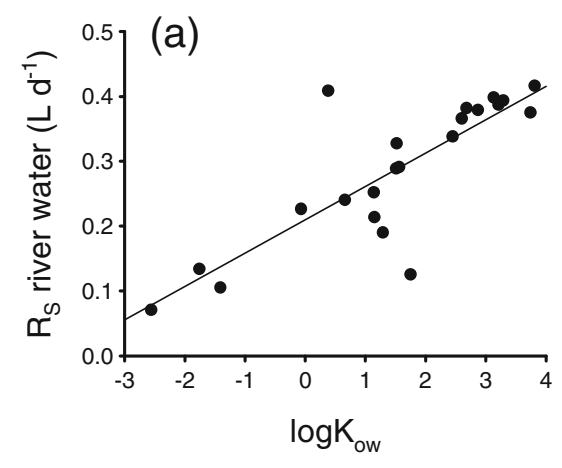

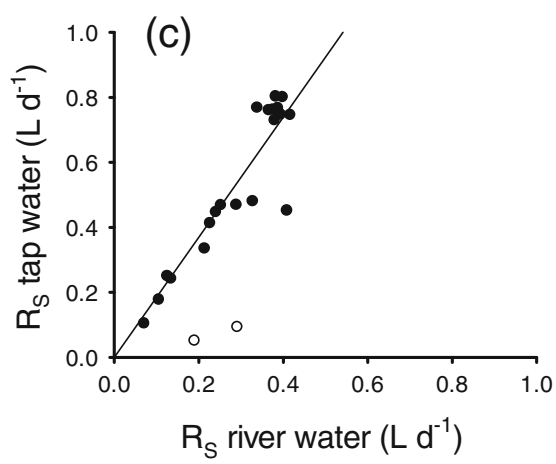

Fig. 3 a Association between the hydrophobicity of a compound $\left(\log K_{\text {ow }}\right.$; octanol-water partitioning coefficient; including corrections for neutral species, see Table 1) and the experimental sampling rate over the first $24 \mathrm{~h}\left(R_{\mathrm{S}}\right)$ by Empore ${ }^{\mathrm{TM}} \mathrm{SDB}$ disks in a channel with flowing river water; the line signifies the fit of a linear regression model $\left(R_{\mathrm{S}}=\right.$ intercept + slope $\left.\log K_{\mathrm{ow}}\right)$. b Association between the $\log K_{\text {ow }}$ of a compound and $R_{\mathrm{S}}$ in a tank with flowing tap water; the line signifies the fit of a linear regression model $\left(R_{\mathrm{S}}=\right.$ intercept + slope $\left.\log K_{\mathrm{ow}}\right)$. $\mathrm{c}$ Correlation between $R_{\mathrm{S}}$ values from river and tap water; the line signifies the fit of a linear regression model without intercept $\left(R_{\mathrm{S}-\text { tap water }}=\right.$ slope $\left.R_{\mathrm{S} \text {-river water }}\right)$ 
(a)

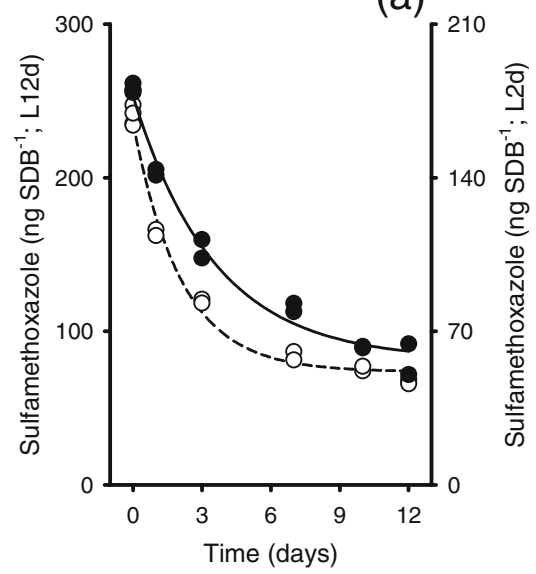

(d)

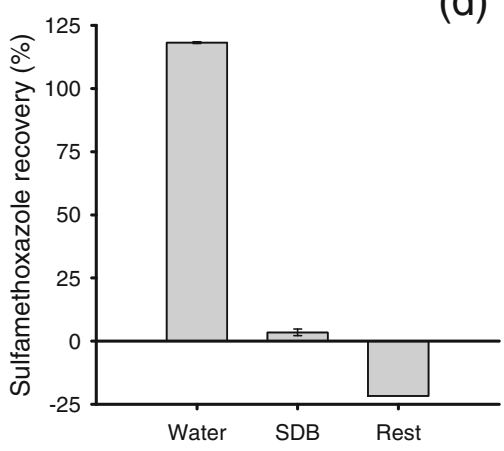

(g)

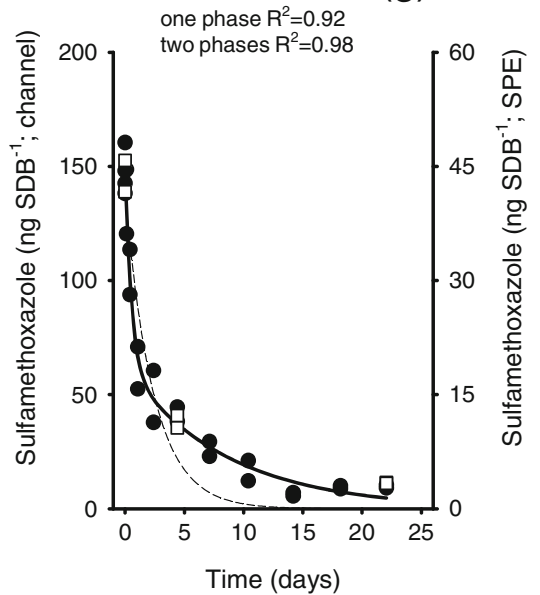

(b)

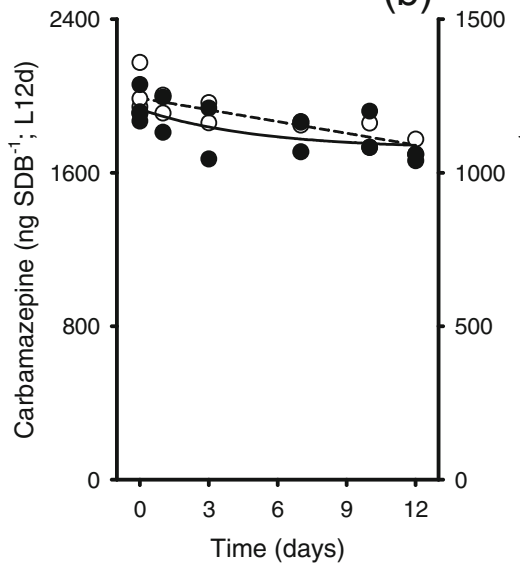

(e)

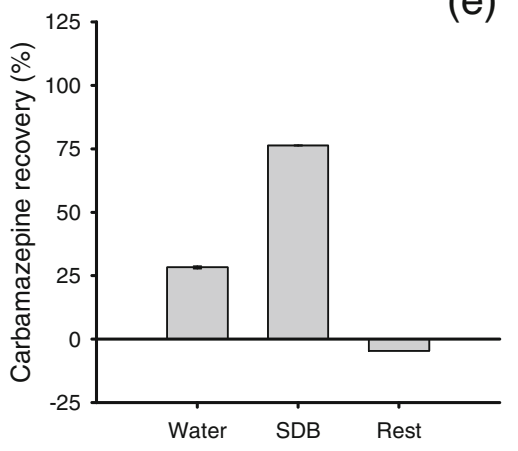

(h)

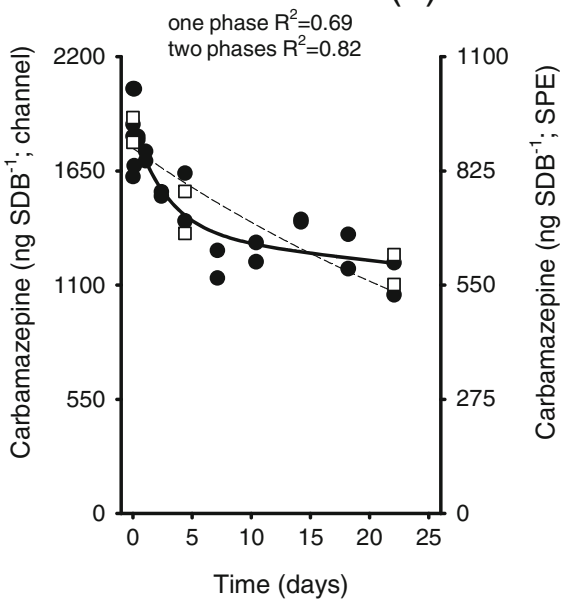

(c)

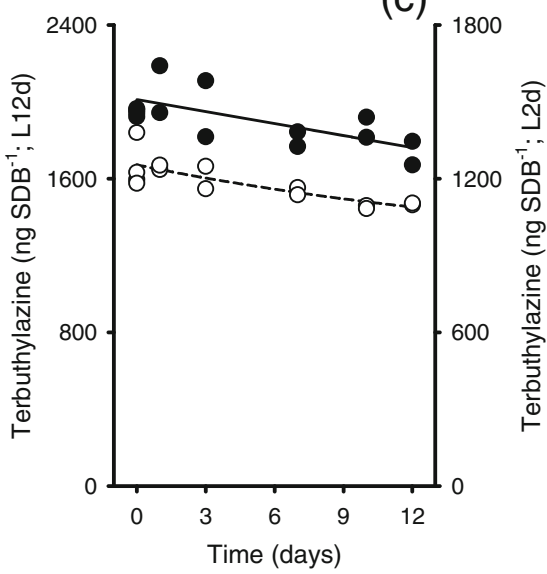

(f)

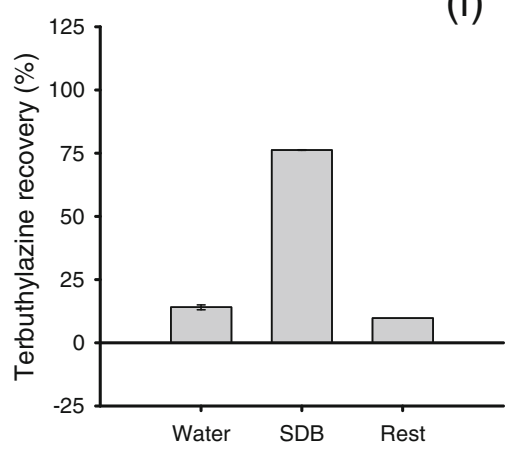

Fig. 4 Top panel: desorption of sulfamethoxazole (a), carbamazepine (b) and terbuthylazine (c) from Empore ${ }^{\mathrm{TM}}$ SDB disks in a channel with river water; disks were loaded for 2 days (L2d disks; open circles, dashed line) or 12 days (L12d disks; filled circles, solid line); lines are fits with a one-phase model (Eq. 3). Middle panel: recovery of sulfamethoxazole (d), carbamazepine (e) and terbuthylazine (f) in water and SDB disks from the mass balance experiment (beaker with tap water;

phase, no desorption occurred from L12d disks, and L2d disks even continued to sorb benzotriazole due to high background concentrations. error bars show the range of the duplicates). Bottom panel: desorption of sulfamethoxazole (g), carbamazepine (h) and terbuthylazine (i) from SDB disks in a circular tank with deionised water; disks were loaded passively (channel; circles and left $y$-axis) or actively (SPE; squares and right $y$-axis); lines are fits with a one-phase (Eq. 3, thin dashed line) or a two-phase model (Eq. 4, solid line)

Compounds with $\log K_{\mathrm{ow}}>2$ desorbed only in small amounts $(<20 \%)$, which made it difficult to fit a one-phase desorption kinetic curve (Eq. 2; Fig. 4b, c; see Fig. S11, ESM, 

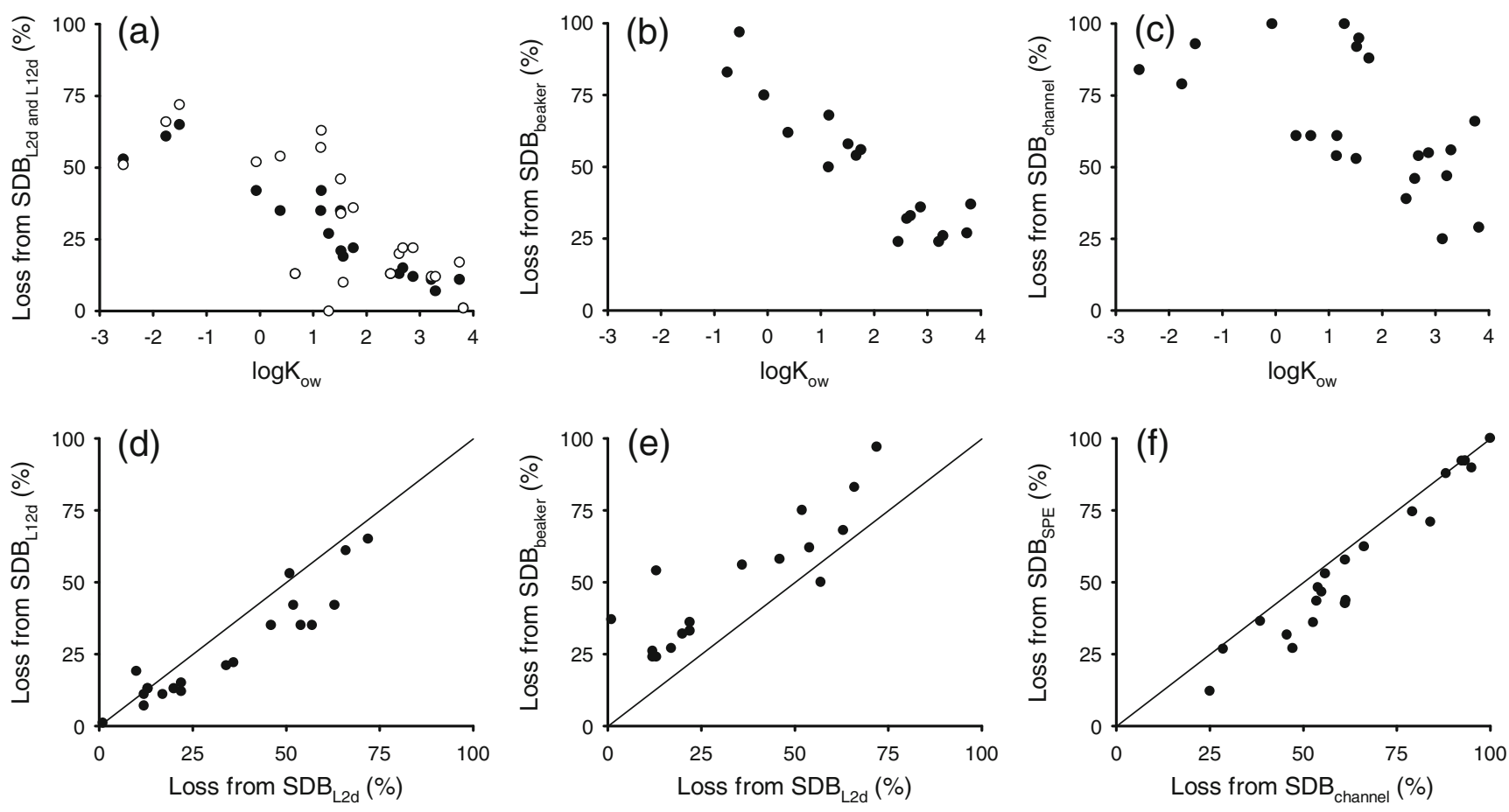

Fig. 5 Top panel, correlations between: the hydrophobicity of a compound $\left(\log K_{\text {ow }}\right.$; octanol-water partitioning coefficient; including corrections for neutral species, see Table 1) and the desorption (perecentage loss) from Empore ${ }^{\mathrm{TM}} \mathrm{SDB}$ disks in river water (a solid circles, disks loaded in river water for 12 days, L12d disks; open circles, disks loaded in river water for 2 days, L2d disks) and tap water

for all graphs). Nevertheless, a clear association between $\log K_{\text {ow }}$ and the desorption potential is apparent (Fig. 5a).

Figure $5 \mathrm{~d}$ shows a robust correlation between the loss from L12d and L2d disks. Most data are slightly below the 1 to 1 line, meaning that L2d disks desorb proportionally more of a compound than L12d disks. Several hypotheses can be put forward and could be tested in further studies. Possibly the L12d disks have acquired a biofilm that reduces the exchange between the disk and the water. Alternatively, over time, compounds may diffuse deeper into the polymer and are thus less readily available for desorption or require more time to desorb.

Mass balances from the beaker experiment (Experiment 4) evidently show that the loss of compounds from the disks in the channel is not attributable to biodegradation or reduced extraction efficiency, as, for example, the amount of sulfamethoxazole that was lost from the disk could be found in the water (with some margin of error; Fig. 4d). The mass balance was not within acceptable limits $( \pm 40 \%)$ for all compounds, some compounds showed large discrepancies which we could not resolve (Table 1). Possibly for both benzotriazole and 5-methyl benzotriazole, the desorbed compounds formed complexes with corroded metal parts as it is known for those corrosion inhibitors [28].

As the water in the beaker was repeatedly exchanged with fresh tap water, background concentrations periodically (b) and deionised water (c). Bottom panel, correlations between: the desorption from L12d and L2d SDB disks in river water (d); desorption from $\mathrm{SDB}$ disks in river water $\left(\mathrm{SDB}_{\mathrm{L} 2 \mathrm{~d}}\right)$ and $\mathrm{SDB}$-disks in tap water $\left(\mathrm{SDB}_{\text {beaker }} ; \mathbf{e}\right)$; desorption from passively $\left(\mathrm{SDB}_{\text {channel }}\right)$ and actively loaded SDB disks $\left(\mathrm{SDB}_{\mathrm{SPE}} ; \mathbf{f}\right)$. Lines indicate 1 to 1 relationships

dropped to 0 . This also allowed for a better assessment of the desorption of the less polar compounds $\left(\log K_{\mathrm{ow}}>2\right.$; Fig. 4e, f; see Fig. S12, ESM, for all graphs). A compound such as terbuthylazine desorbed to $24 \%$ in the beaker, whereas it showed only $11 \%$ desorption in the channel (likely) because of background levels of terbuthylazine in the channel (around $8 \mathrm{ngL}^{-1}$ ). Also for the beaker experiment, there was a clear association between $\log K_{\mathrm{ow}}$ of a compound and its potential to desorb from SDB disks (Fig. 5b).

Figure 5e shows that there is a good association between the percentage of a substance that desorbed in the channel compared to the percentage that desorbed in the beaker. Most values are above the 1 to 1 line, as expected, as the experiment in the beaker favoured desorption compared to the channel experiment for several reasons. First, repeated exchanges with fresh tap water ensured low background concentrations. Second, the temperature was higher, increasing the diffusion coefficients. Third, a shallow housing and slightly higher flow rates were used in the beaker; both are factors that increase transfer over the aqueous boundary layer.

Desorption follows a two-phase model

The desorption to deionised water in the circular tank, with more data points during the initial desorption phase and a 
faster kinetic (higher flow rate, a flat SDB disk housing and a higher temperature), provides further insight into the desorption kinetics. In addition to a one-phase desorption model (i.e. Eq. 3 with the condition that $C_{\mathrm{w}}=0$ ) a twophase desorption model was fitted (Eq. 4). This two-phase model gave an excellent fit, whereas the one-phase model did not align with the data (Fig. 4g-i, see Fig. S13, ESM, for all graphs); this is markedly different from observations made on polyethersulfone-covered C18 disks [[20], where desorption followed a one-phase model. The initial and rapid desorption phase from SDB may represent the fraction of a compound that is sorbed superficially to the disk; the second and slower desorption phase the fraction located deeper into the disk. Some evidence for this hypothesis comes from disks that were loaded with compounds by pulling spiked water through them in an SPE device. Terbuthylazine data show that the desorption of disks loaded by means of SPE clearly lagged the desorption of passively loaded disks (Fig. 4i). When we correlated the loss from actively $\left(\mathrm{SDB}_{\mathrm{SPE}}\right)$ and passively loaded disks $\left(\mathrm{SDB}_{\text {channel }}\right)$, it was evident that passively loaded compounds generally desorbed to a proportionally larger extent than actively loaded compounds (Fig. 5f). The effect was largest for metolachlor (factor 2), where $25 \%$ of passively loaded metolachlor desorbed, whereas only $12 \%$ of actively loaded metolachlor desorbed. When actively loading disks, a larger portion of the compound may end up deeper into the disk than when disks are loaded passively. The portion of the compound that ends up deeper inside the disk may be less readily available for desorption. This observation may explain why some researchers experienced difficulties with desorption studies using SPE-loaded Empore ${ }^{\mathrm{TM}}$ disks (e.g. [19]). Furthermore, this observation may explain the differences observed for L2d and L12d disks (Fig. 5d), in that L12d disks desorb less of a compound compared to L2d disks. Again, this may be caused by the fact that compounds diffuse deeper into the disk over time (i.e. in L12d disks) and are thus less readily available for desorption.

Results from the various desorption trials stress the need for future work where transport or penetration of compounds into and out of the Empore ${ }^{\mathrm{TM}}$ disks has to be addressed. Possibilities would be to use stacks of Empore $^{\mathrm{TM}}$ disks, similar to using stacks of PDMS sheets as described by Rusina and co-workers [31] or cutting layers from passively exposed Empore ${ }^{\mathrm{TM}}$ disks using a cryostat (microtome).

A one-phase sorption model does not produce robust $K_{\mathrm{SDBw}}$ values

In light of the observation concerning a two-phase desorption process - and for illustrative purposes - we fitted the diuron sorption data from Experiments 1 and 2 with a twophase model (Eq. 2, Fig. 6). The inclusion of the two additional parameters did not noticeably affect the quality of the fit during the (slow) sorption in river water (Fig. 6a), but did slightly improve the fit during the (accelerated) sorption in tap water (Fig. 6b). This would imply that for some conditions and some substances, there may be a fast sorption phase with low capacity (possibly superficial adsorption) that is followed by a slower phase with a higher capacity (possibly requiring diffusion deeper into the disk); alternatively, sorption may involve both adsorptive and absorptive process. Although the difference between the two fits appears small, i.e. clearly within the uncertainty of the data, the effect becomes very large when extrapolating the data to obtain the fitted equilibrium values for the apparent partitioning coefficients and the rate constants (Fig. 6c). Consequently, although the one-phase sorption model matches the data rather well over the experimental period (i.e. $R^{2}>0.99$ ), it is not clear if and how it can be extrapolated beyond 8 days (or 25 days). This questions the
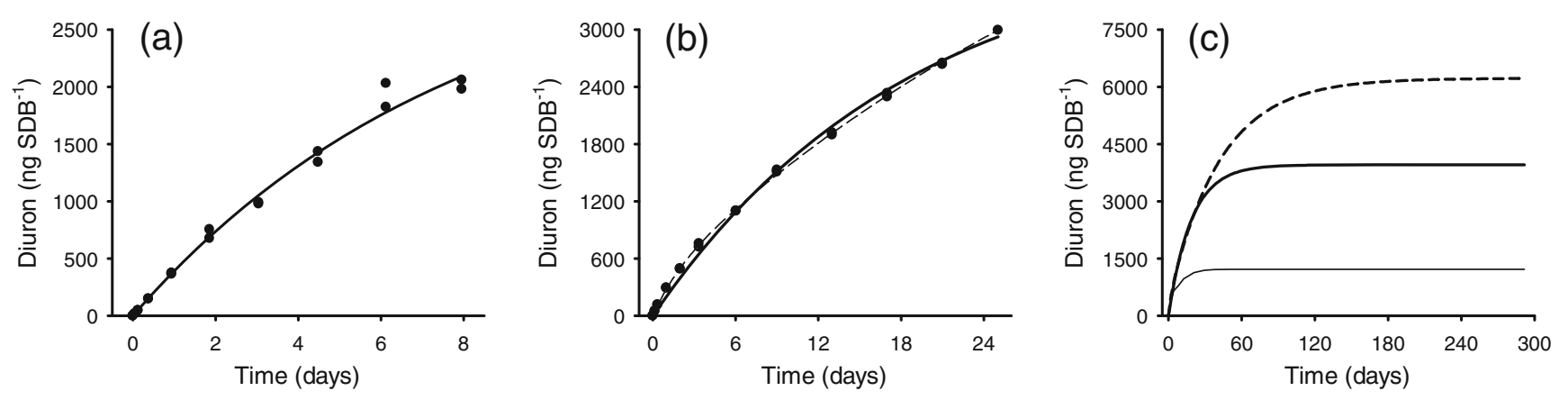

Fig. 6 a Sorption of diuron by Empore ${ }^{\mathrm{TM}}$ SDB disks from river water (Experiment 1) fitted with a one-phase model (Eq. 1). b Sorption of diuron from tap water (Experiment 2) fitted with a one-phase model (solid line) and a two-phase model (Eq. 2, dashed line). c Extrapolations of the diuron models from Experiments 1 and 2; extrapolation of the one-phase model from panel a (thin solid line) and the one- (thick solid line) and two-phase (dashed line) models from panel b. To facilitate comparisons, the extrapolation of the model from panel $\mathbf{a}$ is based on the estimated parameters for diuron from Experiment 1 (panel a; $K_{\mathrm{SDBw}}=9,265 ; k_{\mathrm{e}}=0.13$ day $^{-1}$ ) but using the aqueous concentration of diuron in Experiment $2\left(C_{\mathrm{w}}=383 \mathrm{ngL}^{-1}\right)$ 
robustness of fitted values for the parameters $K_{\mathrm{SDBw}}$ and $k_{\mathrm{e}}$, and thus, we do not report $K_{\mathrm{SDBw}}$ and $k_{\mathrm{e}}$ values.

Implications for use of SDB-RPS Empore ${ }^{\mathrm{TM}}$ disks as passive samplers

The fact that sorption and desorption do not appear to show isotropic kinetics - for any of the tested compounds - signifies a possibly prohibitive obstacle with respect to developing PRCs in combination with SDB-RPS. However, in which way sorption and desorption are indeed not isotropic requires confirmation in an experiment where these processes are investigated simultaneously in a single experiment [32].

As the exact sorption model is not certain and uptake is not fully linear, the most appropriate sampling rate, needed to calculated TWA concentrations from field data, will be generated when the duration of the calibration period matches the duration of field deployments. In addition, it is advantageous to determine sampling rates under realistic environmental conditions (e.g. using river, lake or waste water and appropriate flow rates). For example, the $\mathrm{pH}$ of the sampled matrix may affect speciation of compounds (e.g. sulfamethoxazole) and thus uptake into SDB disks. Finally, the fact that significant desorption can occur is problematic when the intended use of an SDB disk-based passive sampler is to integrate fluctuating concentrations into TWA concentrations as desorption may lead to an underestimation of the TWA concentration.

Acknowledgments The study was funded by SNF project 200021121738 .

\section{References}

1. Greenwood R, Mills GA, Vrana B (2007) Passive sampling techniques in environmental monitoring. Elsevier, Amsterdam

2. Huckins JN, Petty JD, Booij K (2006) Monitors of organic chemicals in the environment: semipermeable membrane devices. Springer, New York

3. Daughton CG (2002) Environmental stewardship and drugs as pollutants. Lancet 360:1035-1036

4. Sumpter JP (2005) Endocrine disrupters in the aquatic environment: an overview. Acta Hydrochim Hydrobiol 33:9-16

5. European Commission (2008) Directive 2008/105/EC of the European Parliament and the Council of the European Union (2008) Environmental Quality Standards in the Field of Water Policy, Amending and Subsequently Repealing Council Directives 82/176/EEC, 83/513/EEC, 84/156/EEC, 84/491/EEC, 86/280/EEC and Amending Directive 2000/60/EC Official Journal of the European Union (http://eur-lex.europa.eu/LexUriServ/ LexUriServ.do?uri=OJ:L:2008:348:0084:0097:EN:PDF)

6. European Commission (2012) Proposal for a Directive of the European Parliament and the Council amending Directives $2000 / 60 / \mathrm{EC}$ and 2008/105/EC as regards priority substances in the field of water policy. vol http://ec.europa.eu/environment/ water/water-dangersub/pdf/com_2011_876.pdf
7. Zabiegała B, Kot-Wasik A, Urbanowicz M, Namieśnik J (2010) Passive sampling as a tool for obtaining reliable analytical information in environmental quality monitoring. Anal Bioanal Chem 396:273-296

8. Alvarez DA, Petty JD, Huckins JN, Jones-Lepp TL, Getting DT, Goddard JP, Manahan SE (2004) Development of a passive, in situ, integrative sampler for hydrophilic organic contaminants in aquatic environments. Environ Toxicol Chem 23:1640-1648

9. Kingston JK, Greenwood R, Mills GA, Morrison GM, Persson LB (2000) Development of a novel passive sampling system for the time-averaged measurement of a range of organic pollutants in aquatic environments. J Environ Monit 2:487-495

10. Escher BI, Quayle P, Muller R, Schreiber U, Mueller JF (2006) Passive sampling of herbicides combined with effect analysis in algae using a novel high-throughput phytotoxicity assay (MaxiImaging-PAM). J Environ Monit 8:456-464

11. MacLeod SL, McClure EL, Wong CS (2007) Laboratory calibration and field deployment of the polar organic chemical integrative sampler for pharmaceuticals and personal care products in wastewater and surface water. Environ Toxicol Chem 26:2517-2529

12. Vermeirssen ELM, Dietschweiler C, Escher BI, van der Voet J, Hollender J (2012) Transfer kinetics of polar organic compounds over polyethersulfone membranes in the passive samplers POCIS and Chemcatcher. Environ Sci Technol 46:6759-6766

13. Vrana B, Vermeirssen ELM, Allan IJ, Kohoutek J, Kennedy K, Mills GA, Greenwood R (2010) Passive sampling of emerging pollutants in the aquatic environment: state of the art and perspectives - a position paper of the expert group of the NORMAN network of reference laboratories for monitoring of emerging environmental pollutants

14. Vermeirssen ELM, Bramaz N, Hollender J, Singer H, Escher BI (2009) Passive sampling combined with ecotoxicological and chemical analysis of pharmaceuticals and biocides - evaluation of three ChemcatcherTM configurations. Water Res 43:903-914

15. Shaw M, Mueller JF (2009) Time integrative passive sampling: how well do Chemcatchers integrate fluctuating pollutant concentrations? Environ Sci Technol 43:1443-1448

16. Mazzella N, Lissalde S, Moreira S, Fo D, Mazellier P, Huckins JN (2010) Evaluation of the use of performance reference compounds in an Oasis-HLB adsorbent based passive sampler for improving water concentration estimates of polar herbicides in freshwater. Environ Sci Technol 44:1713-1719

17. Booij K, Smedes F (2010) An improved method for estimating in situ sampling rates of nonpolar passive samplers. Environ Sci Technol 44:6789-6794

18. Tran ATK, Hyne RV, Doble P (2007) Calibration of a passive sampling device for time-integrated sampling of hydrophilic herbicides in aquatic environments. Environ Toxicol Chem 26:435-443

19. Shaw M, Eaglesham G, Mueller JF (2009) Uptake and release of polar compounds in SDB-RPS Empore(TM) disks; implications for their use as passive samplers. Chemosphere 75:1-7

20. Camilleri J, Morin N, Miège C, Coquery M, Cren-Olivé C (2012) Determination of the uptake and release rates of multifamilies of endocrine disruptor compounds on the polar $\mathrm{C} 18$ Chemcatcher. Three potential performance reference compounds to monitor polar pollutants in surface water by integrative sampling. J Chromatogr 1237:37-45

21. Di Toro DM, Horzempa LM (1982) Reversible and resistant components of PCB adsorption-desorption: isotherms. Environ Sci Technol 16:594-602

22. Vermeirssen ELM, Asmin J, Escher BI, Kwon J-H, Steimen I, Hollender J (2008) The role of hydrodynamics, matrix and sampling duration in passive sampling of polar compounds with Empore $^{\mathrm{TM}}$ SDB-RPS disks. J Environ Monit 10:119-128

23. Lobpreis T, Vrana B, Dominiak E, Dercová K, Mills GA, Greenwood R (2008) Effect of housing geometry on the 
performance of Chemcatcher(TM) passive sampler for the monitoring of hydrophobic organic pollutants in water. Environ Pollut 153:706-710

24. Escher BI, Bramaz N, Quayle P, Rutishauser S, Vermeirssen ELM (2008) Monitoring of the ecotoxicological hazard potential by polar organic micropollutants in sewage treatment plants and surface waters using a mode-of-action based test battery. J Environ Monit 10:622-631

25. Singer H, Jaus S, Hanke I, Lück A, Hollender J, Alder AC (2010) Determination of biocides and pesticides by on-line solid phase extraction coupled with mass spectrometry and their behaviour in wastewater and surface water. Environ Pollut 158:3054-3064

26. Vrana B, Mills GA, Dominiak E, Greenwood R (2006) Calibration of the Chemcatcher passive sampler for the monitoring of priority organic pollutants in water. Environ Pollut 142:333-343

27. Stephens BS, Kapernick A, Eaglesham G, Mueller J (2005) Aquatic passive sampling of herbicides on naked particle loaded membranes: accelerated measurement and empirical estimation of kinetic parameters. Environ Sci Technol 39:8891-8897

28. Finšgar M, Milošev I (2010) Inhibition of copper corrosion by 1,2,3-benzotriazole: a review. Corros Sci 52:2737-2749

29. Schmitt P, Poiger T, Simon R, Freitag D, Kettrup A, Garrison AW (1997) Simultaneous determination of ionization constants and isoelectric points of 12 hydroxy-s-triazines by capillary zone electrophoresis and capillary isoelectric focusing. Anal Chem 69:2559-2566

30. Hansch C, Leo A, Hoekman D (1995) Exploring QSAR. Hydrophobic, Electronic and Steric Constants. ACS Professional Reference Book. American Chemical Society, Washington

31. Rusina TP, Smedes F, Klanova J, Booij K, Holoubek I (2007) Polymer selection for passive sampling: a comparison of critical properties. Chemosphere 68:1344-1351

32. Rusina TP, Smedes F, Koblizkova M, Klanova J (2010) Calibration of silicone rubber passive samplers: experimental and modeled relations between sampling rate and compound properties. Environ Sci Technol 44:362-367 